\title{
BMJ Open Cross-sectional study exploring barriers to adverse drug reactions reporting in community pharmacy settings in Dhaka, Bangladesh
}

Mohammad Nurul Amin, ${ }^{1}$ Tahir Mehmood Khan, ${ }^{2}$ Syed Masudur Rahman Dewan, ${ }^{1}$ Mohammad Safiqul Islam, ${ }^{1}$ Mizanur Rahman Moghal, ${ }^{1}$ Long Chiau Ming ${ }^{3,4}$

To cite: Amin MN, Khan TM, Dewan SMR, et al. Crosssectional study exploring barriers to adverse drug reactions reporting in community pharmacy settings in Dhaka,

Bangladesh. BMJ Open 2016;6:e010912. doi:10.1136/bmjopen-2015010912

- Prepublication history for this paper is available online. To view these files please visit the journal online (http://dx.doi.org/10.1136/ bmjopen-2015-010912).

Received 21 December 2015 Revised 29 March 2016 Accepted 29 April 2016

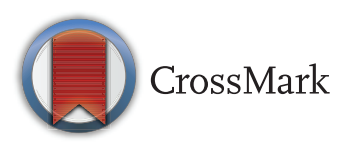

For numbered affiliations see end of article.

Correspondence to Dr Tahir Mehmood Khan; Tahir.mehmood@monash.edu

\section{ABSTRACT}

Objectives: To assess community pharmacists'/ pharmacy technicians' knowledge and perceptions about adverse drug reactions (ADRs) and barriers towards the reporting of such reactions in Dhaka, Bangladesh.

Method: A cross-sectional study was planned to approach potential respondents for the study. A selfadministered questionnaire was delivered to community pharmacists/pharmacy technicians ( $\mathrm{N}=292)$ practising in Dhaka, Bangladesh.

Results: The overall response to the survey was $69.5 \%(n=203)$. The majority of the sample was comprised of pharmacy technicians $(152,74.9 \%)$ who possessed a diploma in pharmacy, followed by pharmacists (37, 18.2\%) and others (12, 5.9\%). Overall, $72(35.5 \%)$ of the respondents disclosed that they had experienced an ADR at their pharmacy, yet more than half $(105,51.7 \%)$ were not familiar with the existence of an ADR reporting body in Bangladesh. Exploring the barriers to the reporting of ADRs, it was revealed that the top four barriers to $A D R$ reporting were 'I do not know how to report (Relative Importance Index (RII) $=0.998)$ ', 'reporting forms are not available (0.996)', 'I am not motivated to report (0.997)' and 'Unavailability of professional environment to discuss about ADR (RII=0.939)'. In addition to these, a majority $(141,69.46 \%)$ were not confident about the classification of $A D R s(R I=0.889)$ and were afraid of legal liabilities associated with reporting ADRs $(\mathrm{RII}=0.806)$. Moreover, a lack of knowledge about pharmacotherapy and the detection of ADRs was another major factor hindering their reporting (RII=0.731).

Conclusions: The Directorate of Drug Administration in Bangladesh needs to consider the results of this study to help it improve and simplify ADR reporting in Bangladeshi community pharmacy settings.

\section{INTRODUCTION}

Adverse drug reactions (ADRs) are a major concern for policymakers since they are a significant cause of in-hospital morbidity and mortality, ${ }^{1}{ }^{2}$ resulting in a considerable

\section{Strengths and limitations of this study}

- Findings from the current study will assist policymakers to understand the challenges to adverse drug reactions (ADRs) reporting in community pharmacy settings and thus to intervene to make the ADR reporting process easier and more accessible to pharmacists and pharmacy technicians practising in Bangladesh.

- The Directorate of Drug Administration in Bangladesh can make the ADR reporting process more efficient by making the reporting forms easier to access.

- Moreover, given that unavailability of a professional environment to discuss about ADR was a major barrier identified to the reporting of ADRs, the Bangladeshi Pharmacy Association and registration councils can play a proactive role in organising frequent continuous education and training events where pharmacists get the opportunity to discuss such experiences with other pharmacists.

- One of the potential limitations is the small number of pharmacists who participated in this study. Nonetheless, the entire sample was representative of Bangladeshi community pharmacy practice settings, and the barriers to ADR reporting identified through this study are important and will help regulatory bodies intervene to improve the reporting of ADRs in Bangladesh.

economic burden both to patients and society as a whole. ${ }^{3}$ The WHO defined an $\mathrm{ADR}$ as "Any response to a drug which is noxious, unintended and occurs at doses used in man for prophylaxis, diagnosis or therapy'. ${ }^{4}$ Patients consuming four or more medicines a day are more likely to have an $\mathrm{ADR}$, and there is therefore a causal relationship between the number of drugs and the occurrence of ADRs. ${ }^{5}$ In 1999-2006, ADRs resulted in 2341 deaths in the USA of America, ${ }^{6}$ and a study conducted at four hospitals in South Africa showed that 2.9\% and 
$16 \%$ of the mortality were due to ADRs and ADR-related complications, respectively. ${ }^{7}$ As well as those taking a number of drugs, special populations (especially elderly patients) are more likely to suffer an ADR in comparison to others. ${ }^{8}$ Postmarketing surveillance is therefore essential to identify the risk factors and cautionary measures for all drugs that are sold and dispensed to the general public. ${ }^{9}$

In 1996, a dedicated ADR department was established under the purview of the Bangladeshi Directorate General of Drug Administration. In the following year, the Bangladeshi Ministry of Health and Family Welfare established an ADR Advisory Committee (ADRAC). The ADR department was entrusted to implement a systematic mechanism for ADR monitoring programme. The department's functions include collection, analysis and compilation of ADRs. ADRAC consists of 10 experts charged with evaluating, analysing and make recommendations for solving problems related to medicinal hazards due to ADRs. ${ }^{10}$ All healthcare professionals in Bangladesh, whether in private or governmental institutions, are encouraged to submit spontaneous ADR reports. Medical doctors or hospital pharmacists may submit an ADR report. Once they have completed the reporting form they should post it to the ADRM Cell. The printed ADR form is available in the Bangladesh National Formulary, Drug Bulletin, published by the Directorate of Drug Administration, as well as on the internet. ${ }^{11}$

To educate healthcare professionals on ADR reporting, ADR Monitoring Workshops have been conducted at several medical colleges and hospitals during which printed ADR reporting forms were distributed. Furthermore, promotional posters on ADR reporting were displayed to remind the healthcare professionals to report ADRs encountered. Notwithstanding these efforts, only 13 ADR cases were reported to ADRAC up to 11 November $2010 .{ }^{10}$ Awareness of ADR reporting has been shown to be low, especially because the existing manual ADR reporting system was not user friendly. ${ }^{10}$

Previous studies have shown that not all ADRs are reported, and most of these studies have recommended the adoption of spontaneous reporting and the provision of education to healthcare workers about the ADR reporting process. $^{12}$ In addition, one of the recent advances in the field of pharmacy is that in developed countries pharmacists are increasingly being given a more clinically active role to ensure patient safety and the effective use of medicines. One aspect of this expansion of the pharmacists' role is that they are given the authority to report ADRs in clinical practice. ${ }^{13}$ In many developing countries, however, pharmacists do not have a formal role in ADR reporting or in pharmacovigilance systems. ${ }^{14}$ ADR reporting is crucial because two independent studies in India have concluded that the some patient groups are particularly at risk of developing ADRs; for example infants, those using cardiovascular drugs and patients receiving four or more types of medication. ${ }^{5}{ }^{15}$ It is, therefore, of the utmost importance for any developing nation to assess pharmacists' and pharmacy technicians' knowledge of ADRs and any barriers to their reporting.

\section{AIMS OF STUDY}

Addressing the situation in Bangladesh, there is no recent significant evidence regarding ADR reporting practice in Bangladesh among community pharmacists/pharmacy technicians. Moreover, the importance of ADRs in Bangladesh is still underestimated. ${ }^{16}$ Considering this, the study was designed to assess community pharmacists' and pharmacy technicians' knowledge and perceptions about ADRs and the barriers towards the reporting of these reactions in Dhaka, Bangladesh.

\section{METHOD}

A cross-sectional study was conducted among community pharmacists/pharmacy technicians in the capital city of Bangladesh (Dhaka). A total of 292 pharmacies were identified in Dhaka as a representative sample for this study. A convenience sampling technique was used to approach potential respondents for the study. The study period was from 1 June 2014 to 10 October 2014. The convenience sampling method is one of the costeffective approaches to conducting a preliminary assessment of the problem explored in this study. Moreover, the sample approached for this study was representative of the Bangladeshi community pharmacists/pharmacy technicians, reducing the risk of bias arising from the convenience sampling method. Keeping in view these advantages many researchers prefer using convenient sampling method instead of other, more thorough methods.

\section{ETHICAL APPROVAL}

A written consent form was obtained from each participant who wished to participate in the study. Participants were assured that all information provided was completely confidential and that the results would be presented anonymously.

\section{VALIDATION OF THE TOOL}

The study tool was adapted and modified from literature previously published on this topic. ${ }^{1}{ }^{17}$ A preliminary version of the questions was generated in line with the context of Bangladeshi community pharmacy practices. This version was thoroughly reviewed by the researcher for the appropriateness and clarity of its content. After corrections/modifications a 27-item questionnaire was finalised in the English language, and this was submitted to the university's Linguistics Department to rectify grammatical mistakes and unclear jargon and to improve the overall readability and clarity of the questions. ${ }^{18} 19$ After receiving the corrected version from the Linguistics Department, the face validity of the tool was assessed by 
means of a pilot study among 23 pharmacists practising in hospital $(n=15)$ and community pharmacy $(n=8)$ settings. The reliability and internal consistency of the tool was tested using Cronbach's $\alpha$ in SPSS V.17. Cronbach's $\alpha$ for this tool was calculated to be 0.77 . In addition, factor analysis was carried out using Bartlett's test of sphericity and Kaiser-Mayer-Olkin measure. The Bartlett's test of sphericity was 0.0000 and Kaiser-Mayer-Olkin measure of sampling adequacy was 0.740 (limit should be more than 0.6) (Scheridan J, Lyndall G. SPSS analysis without anguish: V.10.0 for windows Singapore. Australia: John Wiley \& Sons, 2001).

\section{CONTENTS OF THE STUDY TOOL}

The self-administered, 27-item questionnaire was used to collect community pharmacists'/pharmacy technicians' views about ADRs and barriers to their reporting. The questionnaire comprised of four sections. Section one mainly addressed demographics and pharmacy-related information and consisted of six items (table 1). The seven items in section two assessed the knowledge and perceptions of community pharmacists in respect to the reporting of ADRs (table 2) by means of a nominal (yes/no) scale. Section three was aimed at documenting perceived barriers that may hinder ADR reporting in Bangladeshi community pharmacy settings. This section contained eight items and used a five-point Likert scale (strongly agree, agree, neutral, disagree and strongly disagree) (table 3). Section four was the last section of the questionnaire and comprised six items aiming to record participants' views about 'Factors that might encourage reporting of ADRs in Bangladesh' (table 4).

\begin{tabular}{|c|c|}
\hline Demographics & N (\%) \\
\hline \multicolumn{2}{|l|}{ Gender } \\
\hline Male & $200(98.6)$ \\
\hline Female & $3(1.4)$ \\
\hline Age & $24-55$ years \\
\hline \multicolumn{2}{|l|}{ Education level } \\
\hline Bachelor of pharmacy & 37 (18.2) \\
\hline Diploma in pharmacy & $152(74.9)$ \\
\hline Master of science & $2(0.9)$ \\
\hline Others (bachelors of science/others) & $12(5.9)$ \\
\hline $\begin{array}{l}\text { How many patients/customers visit your } \\
\text { pharmacy on daily basis }\end{array}$ & $35-75$ \\
\hline \multicolumn{2}{|c|}{ Have you seen any ADR cases in your current practice } \\
\hline Yes & $180(88.6)$ \\
\hline No & $23(22.3)$ \\
\hline \multicolumn{2}{|c|}{$\begin{array}{l}\text { Have you reported any ADR seen among your patients in } \\
\text { past } 12 \text { months? }\end{array}$} \\
\hline Yes & 0 \\
\hline No & $203(100.0)$ \\
\hline
\end{tabular}

\section{DATA ANALYSIS}

On completion of data collection, variables were defined and coded into SPSS V.17. Descriptive statistics were used to analyse the data (frequency and percentages; mean $\pm \mathrm{SD})$. In addition, the $\chi^{2}$ test was applied to measure the statistical significance of nominal and ordinal items. ${ }^{20}$ In cases where the cell count was $<5$ among more than $25 \%$ of the cells, however, Fisher's exact test was preferred. Sometimes, due to uneven distribution of responses, the $\chi^{2}$ test gave insignificant results on the ordinal scale. Therefore, a relative importance index (RII) was applied (equation 1$)^{21}$ to identify the main factors responsible for poor ADR reporting among community pharmacists and pharmacy technicians in Bangladesh. Items were ranked base on the RII values, with the item having an RII value closest to one being ranked as the main factor affecting the ADR reporting process. ${ }^{22}$

$$
\mathrm{RII}=\frac{\sum \mathrm{W}}{\mathrm{A} \times \mathrm{N}}(0 \leq \mathrm{RII} \leq 1)
$$

Where: $\mathrm{W}$-is the weight given to each factor by the respondents and ranges from 1 to 5 , (where ' 1 ' is 'strongly disagree' and ' 5 ' is 'strongly agree'); A-is the highest weight (ie, 5 in this case) and; $\mathrm{N}$-is the total number of respondents.

\section{RESULTS}

The overall response to the survey was $69.5 \% \quad(n=203)$, with the overwhelming majority of respondents being male $(200,98.6 \%)$ and aged between 24 and 55 years. The majority of the sample was comprised of pharmacy technicians $(152,74.9 \%)$ possessing a diploma in pharmacy, followed by pharmacists $(37,18.2 \%)$ and others $(12,5.9 \%)$. The average number of prescriptions dispensed by the respondents was between 35 and 75 daily, and about 180 (88.6\%) disclosed that they had seen ADRs in their practice. None of the respondents had reported an ADR in the year up to the time of the study (table 1).

Knowledge about ADRs and their reporting was assessed using the seven items shown in table 2. Overall, $189(93.1 \%)$ of the respondents agreed with the definition of an ADR ( $p=0.169)$ and $195(96.1 \%)$ graded penicillin rash as a correct example of an ADR $(\mathrm{p}=0.424)$. The majority of the respondents (200, $98.5 \%$ ) emphasised the need to confirm that an incident was an ADR before reporting, and believed that reporting an ADR contributes to drug safety (199, $98.1 \%)$. In addition, $72(35.5 \%)$ of the respondents disclosed that they had experienced an ADR at their pharmacy $(p=0.001)$, but more than half $(105,51.7 \%)$ of the respondents were not familiar with the existence of an ADR reporting body in Bangladesh ( $\mathrm{p}=0.032$; table 2$)$.

Exploring the barriers to ADR reporting, it was revealed that 'the lack of a professional setup/body to 
Table 2 Respondents' knowledge about ADRs and their reporting

\begin{tabular}{|c|c|c|c|}
\hline Statements & YES (\%) & NO (\%) & $p$ Value \\
\hline $\begin{array}{l}\text { A response to a drug which is noxious, unintended and occurs at doses } \\
\text { normally used in man for the prophylaxis, diagnosis or therapy of disease, } \\
\text { or for modification of physiological function. Is this the definition of adverse } \\
\text { drug reaction? }\end{array}$ & 189 (93.1\%) & 14 (6.9\%) & 0.169 \\
\hline Rashes caused by Penicillin can be classified as an adverse drug reaction & 195 (96.1\%) & $8(3.9 \%)^{\star}$ & 0.424 \\
\hline In your opinion, do you think that ADR reporting contributes to drug safety & $199(98.1)$ & $4(1.9 \%)$ * & 0.613 \\
\hline $\begin{array}{l}\text { 'It is necessary to be confirmed' that an ADR is related to a particular drug } \\
\text { before reporting }\end{array}$ & 200 (98.5\%) & $3(1.5 \%)$ * & 0.796 \\
\hline Only the names of the suspected drug need to be reported & $139(68.5 \%)$ & $64(31.5 \%)$ & $<0.0001 \dagger$ \\
\hline $\begin{array}{l}\text { Are you aware of the existence of the regulatory body that regulates ADR } \\
\text { reporting in Bangladesh? }\end{array}$ & 105 (51.7\%) & $98(48.3 \%)$ & $0.032 \dagger$ \\
\hline Has any patient come to your pharmacy with symptoms of ADRs & $72(35.5 \%)$ & $131(64.5 \%)$ & $<0.0001 t$ \\
\hline
\end{tabular}

discuss about ADR' ( $\mathrm{p}=0.040)$, 'Insufficient knowledge of pharmacotherapy in detecting ADR' $(p=0.018)$, 'I am not confident whether it is an ADR or not' $(p=0.046)$ and 'fear of legal liability for the reported ADR' $(p=0.045)$ were the statistically significant factors hindering the reporting of ADRs. In most of the cases, however, variation in responses made it impossible to rank the main factors. RII was therefore used to estimate the relative importance of the identified factors. RII analysis revealed that 'I do not know how to report' (RII=0.998), 'reporting forms are not available' (0.996), 'I am not motivated to report' (0.997) and 'Lack of a professional environment to discuss ADRs' (RII=0.939) were the top four barriers to ADR reporting. In addition, a majority $(141,69.46 \%)$ were not confident about the classification of ADRs (RII $=0.889$ ) and were afraid of legal liabilities associated with reporting ADRs
(RII=0.806). Moreover, insufficient knowledge about pharmacotherapy and the detection of ADRs was another important factor hindering the reporting of ADRs (RII $=0.731)$. Details are shown in table 3 .

The last part of the questionnaire was about the facilitators that might motivate respondents to report an ADR. Although none of these six items were statistically significant, RII analysis revealed all six items as a top priority with RIIs of more than 0.90 , thus emphasising the need for a more robust ADR reporting system in Bangladesh (table 4).

\section{DISCUSSION}

This is perhaps the first study aiming to explore this critical aspect in Bangladeshi community pharmacy practice. Overall, the current sample was an accurate

Table 3 Barriers to ADRs reporting

\begin{tabular}{|c|c|c|c|c|c|c|c|c|}
\hline & $\begin{array}{l}\text { Strongly } \\
\text { agree (\%) }\end{array}$ & $\begin{array}{l}\text { Agree } \\
(\%)\end{array}$ & $\begin{array}{l}\text { Neutral } \\
(\%)\end{array}$ & $\begin{array}{l}\text { Disagree } \\
(\%)\end{array}$ & $\begin{array}{l}\text { Strongly } \\
\text { disagree } \\
\text { (\%) }\end{array}$ & $\begin{array}{l}\text { Relative } \\
\text { index }\end{array}$ & Rank & $\begin{array}{l}p \\
\text { Value }\end{array}$ \\
\hline $\begin{array}{l}\text { Reporting forms are not } \\
\text { available }\end{array}$ & $200(98.5)$ & $2(1.0)$ & $1(0.5)$ & 0 & 0 & 0.996 & 2 & 0.554 \\
\hline $\begin{array}{l}\text { Reporting may be time } \\
\text { consuming }\end{array}$ & 0 & $74(36.5)$ & $89(43.8)$ & $40(19.7)$ & 0 & 0.633 & 8 & 0.0112 \\
\hline $\begin{array}{l}\text { I fear legal liability for the } \\
\text { reported ADR }\end{array}$ & 78 (38.4) & $66(32.5)$ & $46(22.7)$ & $13(6.4)$ & 0 & 0.806 & 6 & $0.045^{\star}$ \\
\hline I am not motivated to report & $188(92.6)$ & 7 (3.4) & $8(3.9)$ & 0 & 0 & 0.977 & 3 & 0.080 \\
\hline I do not know how to report & $201(99.0)$ & $2(1.0)$ & 0 & 0 & 0 & 0.998 & 1 & 0.789 \\
\hline $\begin{array}{l}\text { I am not confident whether it } \\
\text { is an ADR or not }\end{array}$ & $141(69.5)$ & $34(16.7)$ & $7(3.4)$ & $19(9.4)$ & $2(1.0)$ & 0.889 & 5 & $0.046^{\star}$ \\
\hline $\begin{array}{l}\text { Insufficient knowledge of } \\
\text { pharmacotherapy in } \\
\text { detecting ADR }\end{array}$ & $71(35.0)$ & $58(28.6)$ & $11(5.4)$ & $59(29.1)$ & $4(2.0)$ & 0.731 & 7 & $0.018^{*}$ \\
\hline $\begin{array}{l}\text { Lack of professional setup/ } \\
\text { body to discuss about ADR }\end{array}$ & 157 (77.3) & 37 (18.2) & $2(1.0)$ & $7(3.4)$ & 0 & 0.939 & 4 & $0.040^{*}$ \\
\hline
\end{tabular}


Table 4 Factors encouraging reporting of ADRs

\begin{tabular}{|c|c|c|c|c|c|c|c|c|}
\hline & $\begin{array}{l}\text { Strongly } \\
\text { agree (\%) }\end{array}$ & $\begin{array}{l}\text { Agree } \\
(\%)\end{array}$ & $\begin{array}{l}\text { Neutral } \\
(\%)\end{array}$ & $\begin{array}{l}\text { Disagree } \\
(\%)\end{array}$ & $\begin{array}{l}\text { Strongly } \\
\text { disagree (\%) }\end{array}$ & $\begin{array}{l}\text { Relative } \\
\text { index }\end{array}$ & Rank & p Value \\
\hline There is an obligation to do so & $201(99.0)$ & $2(1.0)$ & 0 & 0 & 0 & 0.998 & 2 & 0.558 \\
\hline $\begin{array}{l}\text { Guidelines on reporting and } \\
\text { bulletins on ADRs provided } \\
\text { regularly }\end{array}$ & $200(98.5)$ & $3(1.5)$ & 0 & 0 & 0 & 0.997 & 3 & 0.591 \\
\hline $\begin{array}{l}\text { I receive feedback from } \\
\text { relevant authorities }\end{array}$ & $114(56.2)$ & $89(43.8)$ & 0 & 0 & 0 & 0.912 & 6 & 0.168 \\
\hline $\begin{array}{l}\text { A simple method of reporting } \\
\text { is implemented }\end{array}$ & $178(87.7)$ & $22(10.8)$ & $3(1.5)$ & 0 & 0 & 0.972 & 5 & 0.068 \\
\hline $\begin{array}{l}\text { If there is toll free number } \\
\text { provided by the relevant } \\
\text { authorities }\end{array}$ & $198(97.5)$ & $5(2.5)$ & 0 & 0 & 0 & 0.995 & 4 & 0.421 \\
\hline $\begin{array}{l}\text { I am willing to report ADR at } \\
\text { the request of a patient }\end{array}$ & $202(99.5)$ & $1(0.5)$ & 0 & 0 & 0 & 0.999 & 1 & 0.580 \\
\hline
\end{tabular}

representation of Bangladeshi community pharmacy practices. The Directorate of Drug Administration (DDA) was established in 1996 under the guidance of the WHO. ${ }^{23}$ The DDA's activities to improve awareness of ADRs include the creation of a 10 member ADR Advisory Committee 'to evaluate, analyse and make recommendations for solving problems of medicinal hazards due to ADRs'. During its first decade the DDA managed to agree on the protocol for a reporting process and to issue ADR reporting forms. In addition the DDA claims that they have organised occasional workshops and events to increase awareness among healthcare professionals about ADR reporting. The results of the current study, however, appear to contradict these claims, since almost the whole sample indicated that they were not exposed to activities conducted by the ADR reporting body. Similar to a study conducted in Malaysia, the community pharmacists involved in this study lack information and initiative to report an ADR. Barriers which prevent community pharmacists from ADR reporting identified from the Malaysian study, such as a lack of knowledge on submitting reports $(\mathrm{RII}=0.998)$ as well as access to the ADR reporting form $(\mathrm{RII}=0.996)$ resonate with the scenario in Bangladesh. ${ }^{24}$

Similar results are reported by other studies carried out in developing countries which address the barriers to the ADR reporting process. ${ }^{1} 17$ Another main barrier to $\mathrm{ADR}$ reporting in the current sample was a lack of motivation to report an $\mathrm{ADR}(195,96.0 \%, \mathrm{RII}=0.977)$ and insufficient knowledge about the pharmacotherapy and ADR detection $(129,63.6 \%$, RII=0.731). Perhaps due to the lack of knowledge about the pharmacotherapy, a majority $(175,86.2 \%)$ were not confident about classifying an event as being an ADR and this is one reason why there is an urgent need for a professional body in Bangladesh where community pharmacists and technicians can pool their experiences about events so as to develop knowledge about classifying and reporting ADRs. A recent study from the US reported that improved knowledge about ADRs encourages the reporting of such events to the US Food and Drug Administration. ${ }^{25}$ Knowledge improvement activities $^{2}$ DDA may, therefore, be able to increase the proportion of ADRs reported by Bangladeshi community pharmacists and technicians practising over the counter.

Unlike in other studies, the time required to make a report is not found to be one of the main barriers to ADR reporting $(\mathrm{RII}=0.633) .{ }^{25}$ In the current study reporting time was not found to a main barrier to the ADR reporting. In addition, addressing the facilitators to ADR reporting, most agreed on the need to simplify the ADR reporting process and emphasised the need for feedback from their reports and speeded-up communication processes with the authorities. One of the most concerning issues raised by the current sample is that the majority of the respondents are pharmacy technicians who are practising freely in the community pharmacies. This, in fact, is a very common problem in developing countries. In context of ADR management and drug sales, however, relying on pharmacy technicians for over-the-counter prescriptions may be fatal: for example, a case report from Saudi Arabia recounts the death of a patient who was administered a influenza shot by a technician working at a community pharmacy in Jeddah. ${ }^{26}$ This further intensifies the need for the DDA in Bangladesh to take on a more proactive role so as to ensure the availability of qualified pharmacists in community pharmacies and to ensure the safe and rational dispensing of drugs. Moreover, there is an immediate need for training of the community pharmacy practitioners about the ADR reporting process in Bangladesh, $72(35.5 \%)$ of the respondents disclosed patients reporting ADRs to them, but none of these were actually reported due to poor awareness of the ADR reporting process. 


\section{LIMITATIONS}

Only pharmacists and technicians practicing in Dhaka city responded to the survey. Moreover, the majority of the respondents were male pharmacy technicians having a diploma in pharmacy, a more balanced conclusion about the barrier to ADR reporting can be drawn if the future studies try addressing the similar question in a larger number comprised of pharmacists.

\section{CONCLUSIONS}

ADR reporting in Bangladeshi community pharmacy settings is not fully established and reporting of ADRs in community pharmacy practice is not yet established. Most of the respondents disclosed a lack of familiarity with the reporting system implemented by DDA Bangladesh, and this was found to be the main factor hindering the effectiveness of ADR reporting. DDA needs to consider the results of this study as a basis to improve and simplify ADR reporting in Bangladeshi community pharmacy settings.

\section{Author affiliations}

${ }^{1}$ Department of Pharmacy, Noakhali Science and Technology University, Noakhali, Bangladesh

${ }^{2}$ School of Pharmacy, Monash University Malaysia, Selangor, Malaysia ${ }^{3}$ Unit for Medication Outcomes Research and Education (UMORE), Pharmacy, School of Medicine, University of Tasmania, Hobart, Tasmania, Australia ${ }^{4}$ Vector-borne Diseases Research Group (VERDI), Faculty of Pharmacy, Universiti Teknologi MARA (UiTM), Puncak Alam, Malaysia

Acknowledgements The authors would like to thank The Directorate General of Drug Administration (DGDA) under the Ministry of Health and Family Welfare, Government of the People's Republic of Bangladesh for providing ethical approval to conduct this study. The authors also would like to thank Dr Jonathan Richardson (Academic Research Editors) in reviewing and editing the manuscript. This work was supported by Academic and Research Assimilation grants: 600-RMI/DANA5/3/ARAS(46/2015). The authors would like to express their gratitude to Ministry of Higher Education and Universiti Teknologi MARA, Malaysia for financial support for this research. The funders had no role in study design, data collection and analysis, decision to publish or preparation of the manuscript.

Contributors MNA, SMRD, MSI, MRM contributed to data collection, data entry, data analysis, background and methods. TMK and LCM contributed to concept/study design, data analysis, draft manuscript and final proof reading.

Funding Ministry of Higher Education and Universiti Teknologi MARA, Malaysia (600-RMI/DANA5/3/ARAS(46/2015).

Competing interests None declared.

Patient consent Obtained.

Ethics approval The study protocol was approved by The Directorate General of Drug Administration (DGDA) under the Ministry of Health and Family Welfare, Government of the People's Republic of Bangladesh.

Provenance and peer review Not commissioned; externally peer reviewed.

Data sharing statement All data are presented in the paper. No additional data are available.

Open Access This is an Open Access article distributed in accordance with the Creative Commons Attribution Non Commercial (CC BY-NC 4.0) license, which permits others to distribute, remix, adapt, build upon this work noncommercially, and license their derivative works on different terms, provided the original work is properly cited and the use is non-commercial. See: http:// creativecommons.org/licenses/by-nc/4.0/

\section{REFERENCES}

1. Mahmoud MA, Alswaida $\mathrm{Y}$, Alshammari T, et al. Community pharmacists' knowledge, behaviors and experiences about adverse drug reaction reporting in Saudi Arabia. Saudi Pharm $J$ 2014;22:411-18.

2. McKay AJ, Newson RB, Soljak M, et al. Are primary care factors associated with hospital episodes for adverse drug reactions? A national observational study. BMJ Open 2015;5:e008130.

3. Gyllensten H, Rehnberg C, Jönsson AK, et al. Cost of illness of patient-reported adverse drug events: a population-based cross-sectional survey. BMJ Open 2013;3:e002574.

4. World Health Organization. Requirements for adverse reaction reporting. Geneva, Switzerland: WHO, 1975.

5. Kurian J, Mathew J, Sowjanya K, et al. Adverse drug reactions in hospitalized pediatric patients: a prospective observational study. Indian J Pediatr 2016;83:414-19.

6. Shepherd G, Mohorn $\mathrm{P}$, Yacoub $\mathrm{K}$, et al. Adverse drug reaction deaths reported in United States vital statistics, 1999-2006. Ann Pharmacother 2012;46:169-75.

7. Mouton JP, Mehta U, Parrish AG, et al. Mortality from adverse drug reactions in adult medical inpatients at four hospitals in South Africa: a cross-sectional survey. $\mathrm{Br} J$ Clin Pharmacol 2015;80:818-26.

8. Davies EA, O'Mahony MS. Adverse drug reactions in special populations - the elderly. Br J Clin Pharmacol 2015;80: 796-807.

9. Chen BK, Yang YT. Post-marketing surveillance of prescription drug safety: past, present, and future. J Leg Med 2013;34:193-213.

10. Rahman MS, Haque M. Pharmacovigilance: Bangladesh situation. Pharmacovigilance systems and rational use of drugs: an integrated approach. Delhi, India: Lady Hardringe Medical College, 2010.

11. Ministry of Health and Family Welfare of Bangladesh. Adverse Drug Reactions Reporting Form. 2015. http://www.mph-bd.com/images/ article-images/ADR\%20reporting_form.pdf (accessed 10 Dec 2015).

12. Nahar N, Karim A, Paul P, et al. Response of reporting adverse drug reactions among medical practitioners. Bangladesh Med $\mathrm{J}$ 2011;40:13-18.

13. van Grootheest $\mathrm{K}$, Olsson $\mathrm{S}$, Couper $\mathrm{M}$, et al. Pharmacists' role in reporting adverse drug reactions in an international perspective. Pharmacoepidemiol Drug Saf 2004;13:457-64.

14. Hadi MA, Helwani R, Long CM. Facilitators and barriers towards adverse drug reaction reporting: perspective of Malaysian hospital pharmacists. J Pharm Health Serv Res 2013;4:155-8.

15. Palaniappan M, Selvarajan S, George M, et al. Pattern of adverse drug reactions reported with cardiovascular drugs in a tertiary care teaching hospital. J Clin Diagn Res 2015;9:FC01-04.

16. Begum ZA, Sultana S, Umar BU, et al. Study of adverse drug reactions in outpatient departments of a teaching hospital. Bangladesh J Pharmacol 2012;7:104-7.

17. Khan TM. Community pharmacists' knowledge and perceptions about adverse drug reactions and barriers towards their reporting in Eastern region, Alahsa, Saudi Arabia. Ther Adv Drug Saf 2013;4:45-51.

18. Jensen MP. Questionnaire validation: a brief guide for readers of the research literature. Clin J Pain 2003;19:345-52.

19. Wild D, Eremenco S, Mear I, et al. Multinational trialsrecommendations on the translations required, approaches to using the same language in different countries, and the approaches to support pooling the data: the ISPOR Patient-Reported Outcomes Translation and Linguistic Validation Good Research Practices Task Force report. Value Health 2009;12:430-40.

20. Boone HN, Boone DA. Analyzing likert data. J Extension 2012;50:1-5.

21. Elbarkouky MM. A Multi-Criteria Prioritization Framework (MCPF) to assess infrastructure sustainability objectives. J Sust Dev 2012;5:p1.

22. Gündüz M, Nielsen $Y$, Özdemir M. Quantification of delay factors using the relative importance index method for construction projects in Turkey. J Manage Eng 2013;29:133-9.

23. Administration. DGoD. ADR Monitoring. 2014. http://www.dgda.gov. bd/index.php/2013-03-31-04-35-57/adrm-reaction-monitoring (accessed 10 Jan 2015).

24. Elkalmi RM, Hassali MA, Ibrahim MI, et al. Community pharmacists' attitudes, perceptions, and barriers toward adverse drug reaction reporting in Malaysia: a quantitative insight. J Patient Saf 2014;10:81-7.

25. Gavaza P, Brown CM, Lawson KA, et al. Pharmacist reporting of serious adverse drug events to the Food and Drug Administration. $J$ Am Pharm Assoc 2012;52:e109-12.

26. Almalak H, Albluwi Al, Alkhelb DA, et al. Students' attitude toward use of over the counter medicines during exams in Saudi Arabia. Saudi Pharm J 2014;22:107-12. 